\title{
Evaluation of Different Modalities for Partial Thumb Reconstruction
}

\author{
ELYOUNSI M.M, M.Sc.; AHMED KAMAL, M.D.; MOHAMED ABDELRAHIM, M.D.; \\ SABAPATHY S.R., F.R.C.S. and ELSONBATY M.A., M.D.
}

The Department of Plastic Surgery, Faculty of Medicine, Assiut University

\section{INTRODUCTION}

The thumb considers a part of interesting significance for hand work. Basically, it is a solitary unit that is adjusted against every one of the four fingers. The commitment of the thumb to get a good grasping is not reliant on great skin sensibility, in spite of the fact that sensibility must be closing typical for small object controls [1].

The essential supporter of the flexibility of the human hand is the opposable thumb, which is basic for the compelling taking care of and investigation of fine objects. The broad territory of contact between the finger pads of the thumb and index finger is a particularly human trademark [2].

The hand, as the human organ, is in the focal point of day by day life exercises in callings and games. In this exceptional position, the hand is constantly presented to wounds and abuse [3].

The thumb has a part in roughly $40 \%$ of hand capacity; traumatic loss in this manner brings about significant disability [4].

Traumatic loss of a thumb brings about useful weakness. Numerous reconstructive modalities have been depicted to address these losses. Any technique is of advantage, compared with nothing. However, each of the techniques offers advantages and drawbacks and might be more suitable in certain circumstance [5].

A perfect reconstructed thumb would have satisfactory length, a sensate, non-tender tip, have security and be situated to meet alternate digits, with a sufficient first web space [5].

Aim of the work:

Our objectives in this study are:

- Formulating a strategic approach for distal thumb reconstruction.
- Study of different modalities of distal thumb reconstruction and evaluation of each modality regarding its sensation, stability, length, mobility, Position, and pain-free function.

\section{PATIENTS AND METHODS}

This prospective study was conducted between January 2014 and January 2016 on 38 patients, attending outpatient clinic of Plastic Surgery, Hand and Microsurgery department Ganga hospital and medical center, Coimbatore, Tamil Nadu, India. These patients were presented with partial thumb amputation extends from the interphalangeal joint to the thumb tip (distal third) secondary to trauma and all requiring soft tissue reconstruction. This is a conjoined collaboration between Plastic Surgery Department, Assiut University hospital, Egypt and Plastic Surgery, Hand and Microsurgery department Ganga hospital, India. Informed written consent was signed by all patients under the study. A special sheet had been fulfilled for every patient included in this study (age, sex, occupation, date of assessment, diagnosis, sensory assessment, two point discrimination, mono-filament test, strength measurement, sterognosis and Kapandji Score).

These patients were assessed to be candidate for:

1- First dorsal metacarpal artery flap $(n=13)$.

2- Moberg flap ( $n=4)$.

3- V-Y Advancement flap ( $n=6)$.

4- Cross finger flap $(n=15)$.

Follow-up assessments were performed by the same doctor and physiotherapist at 3 months, 6 months and 1 year after the procedure and the assessment included the following:

- Measuring the static and moving 2 point discrimination on the flap, on the donor sites and on the 
contralateral thumb with a Disk-criminator to assess the innervations density.

- Performing the Semmes-Weinstien Monofilament test on the flap and on the donor sites to assess the sensory threshold.

- Checking the grip and pinch strength on the

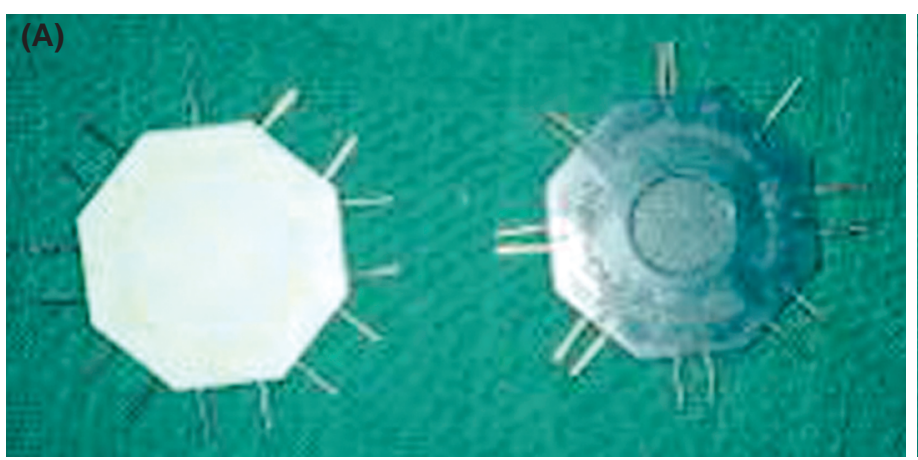

affected and contralateral hands with a Jamar dynamometer and pinch meter.

- Performing a Pickup test to assess stereognosis, where the patient had to pick up and identify 12 objects (pill, coin, button, key, paper clip, safety pin, spoon, cube, marble, rubber band, string and pencil).
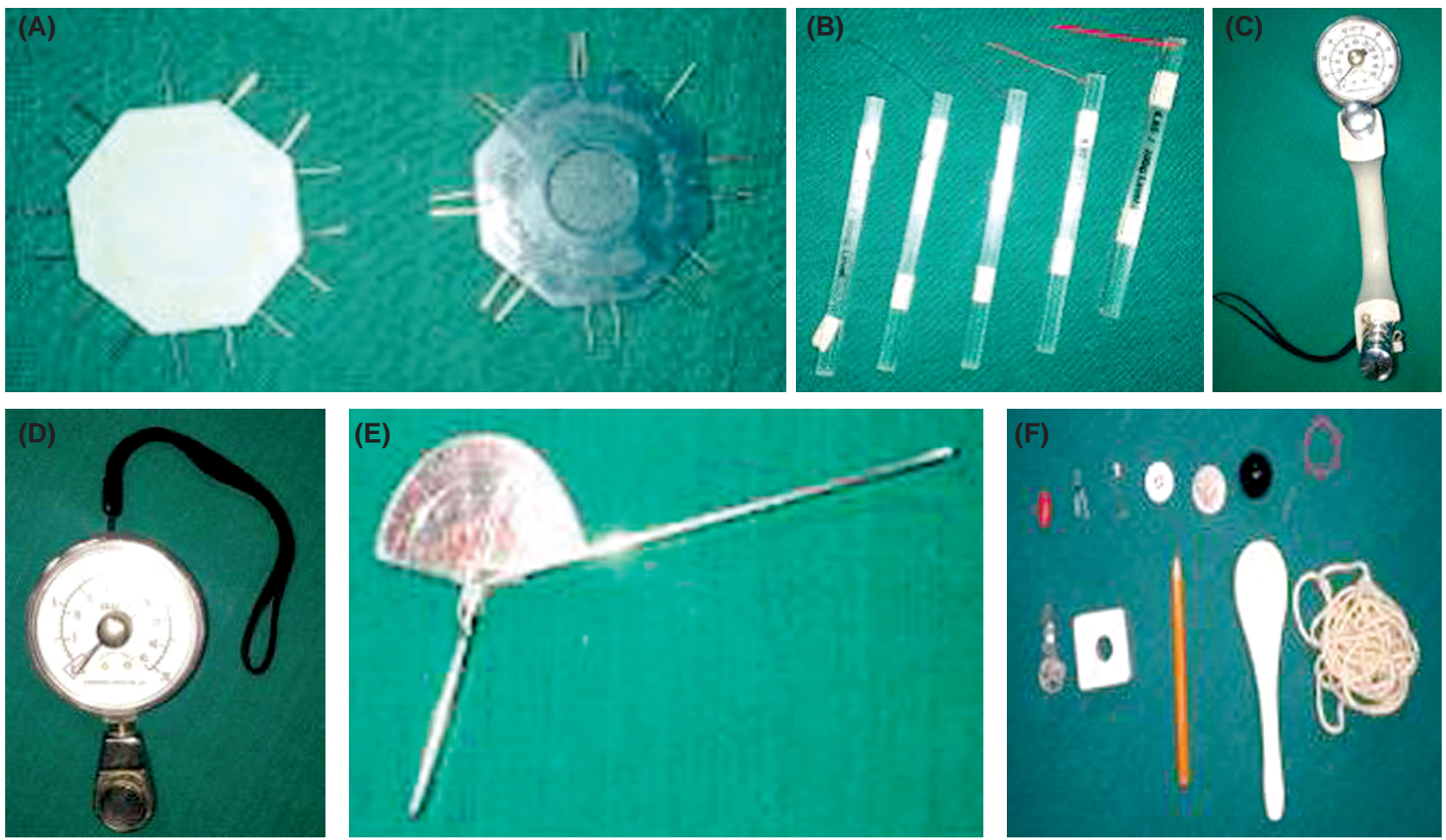

Fig. (1): (A): Disk-Criminator, (B): Monofilament Used in Semmes-Weinstien test, (C): Jamar dynamometer, (D): Jamar pinch meter, (E): Goniometer, (F): Objects used for the pick-up test.

\section{Performing a Kapandji Score:}

The Kapandji score is a tool useful for assessing the oppositon of the thumb based on where on their hand the patient is able to touch with the tip of their thumb.

\begin{tabular}{ll}
\hline Score & \multicolumn{1}{c}{ Location achieved } \\
\hline 1 & Radial side of the proximal phalanx of the index finger \\
2 & Radial side of the middle phalanx of the index finger \\
3 & Tip of the index finger \\
4 & Tip of the middle finger \\
5 & Tip of the ring finger \\
6 & Tip of the little finger \\
7 & Distal interphalangeal joint crease of the little finger \\
8 & Proximal interphalangeal jointcrease of the little finger \\
9 & Metacarpophalangeal joint crease of the little finger \\
\hline
\end{tabular}

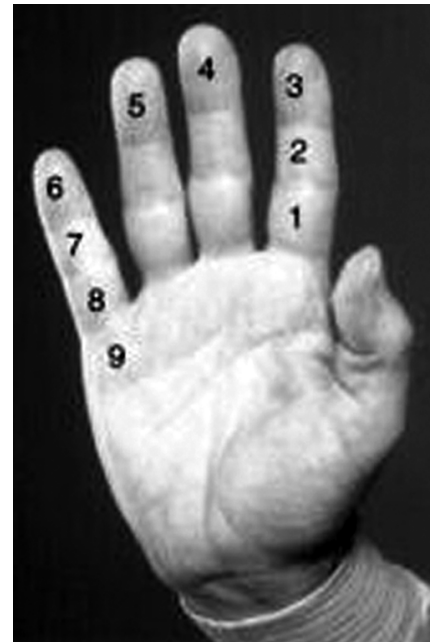

Fig. (2): Kapandji Score [6].

Other important tool which aid in the diagnosis, staging, local extent and follow-up of thumb reconstruction is radiologic $\mathrm{X}$-ray study pre-operative, 1 month, 3 month, 6 month and 1 year postoperative. 


\section{RESULTS}

This study was conducted upon thirty eight patients of distal thumb amputation. These patients were presented with thumb amputation extends from the interphalangeal joint to the thumb tip (distal third) secondary to trauma and all requiring soft tissue reconstruction in a period of 24 months from January 2014 to January 2016. The patients under this prospective study divided into four groups according to the method of reconstruction. $p$-value consider significant if $<0.05$.
Table (1): Personal characteristics of the studied patient.

\begin{tabular}{lcl}
\hline & No. & $\%$ \\
\hline Sex: & & \\
Male & 35 & 92.1 \\
Female & 3 & 7.9 \\
Age: (years) & & \\
Mean \pm SD & $12.75 \pm 39.97$ & \\
$\quad$ Range & $6.9-6 . .9$ & \\
Occupation: & & \\
Employee & 9 & 23.7 \\
Free business & 4 & 10.5 \\
Skilled worker & 2 & 5.3 \\
Student & 3 & 7.9 \\
$\quad$ Unskilled worker & 20 & 52.6 \\
\hline
\end{tabular}

Table (2): Static 2PD.

\begin{tabular}{|c|c|c|c|c|}
\hline \multirow{2}{*}{ Static 2PD } & Cross finger flap & V-Y flap & Moberg flap & FDMA \\
\hline & Mean \pm SD & Mean \pm SD & Mean \pm SD & Mean \pm SD \\
\hline Unaffected & $4.33 \pm 0.49$ & $4.17 \pm 0.41$ & $4.25 \pm 0.50$ & $4.54 \pm 0.52$ \\
\hline Affected & $14.40 \pm 1.68$ & $4.83 \pm 0.41$ & $5.00 \pm 0.00$ & $12.85 \pm 3.29$ \\
\hline$p$-value & 0.000 & 0.027 & 0.040 & 0.000 \\
\hline
\end{tabular}

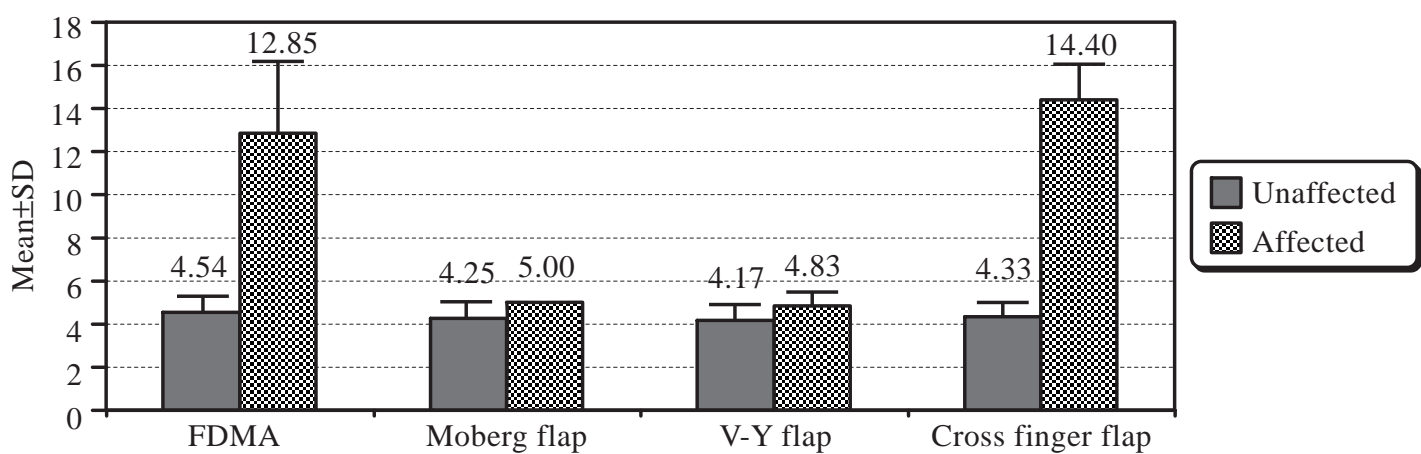

Table (2): Represents static 2PD in patients who suffered partial thumb amputation at distal third, from this table it was found that there were statistical significant differences between affected and unaffected groups in all domains.

Table (3): Moving 2PD.

\begin{tabular}{|c|c|c|c|c|}
\hline \multirow{2}{*}{ Moving 2PD } & FDMA & Moberg flap & V-Y flap & Cross finger flap \\
\hline & Mean \pm SD & Mean \pm SD & Mean \pm SD & Mean \pm SD \\
\hline Unaffected & $4.15 \pm 0.38$ & $4.25 \pm 0.50$ & $4.17 \pm 0.41$ & $4.33 \pm 0.49$ \\
\hline Affected & $11.92 \pm 2.75$ & $5.00 \pm 0.00$ & $4.83 \pm 0.41$ & $13.80 \pm 2.21$ \\
\hline$p$-value & 0.000 & 0.040 & 0.027 & 0.000 \\
\hline
\end{tabular}

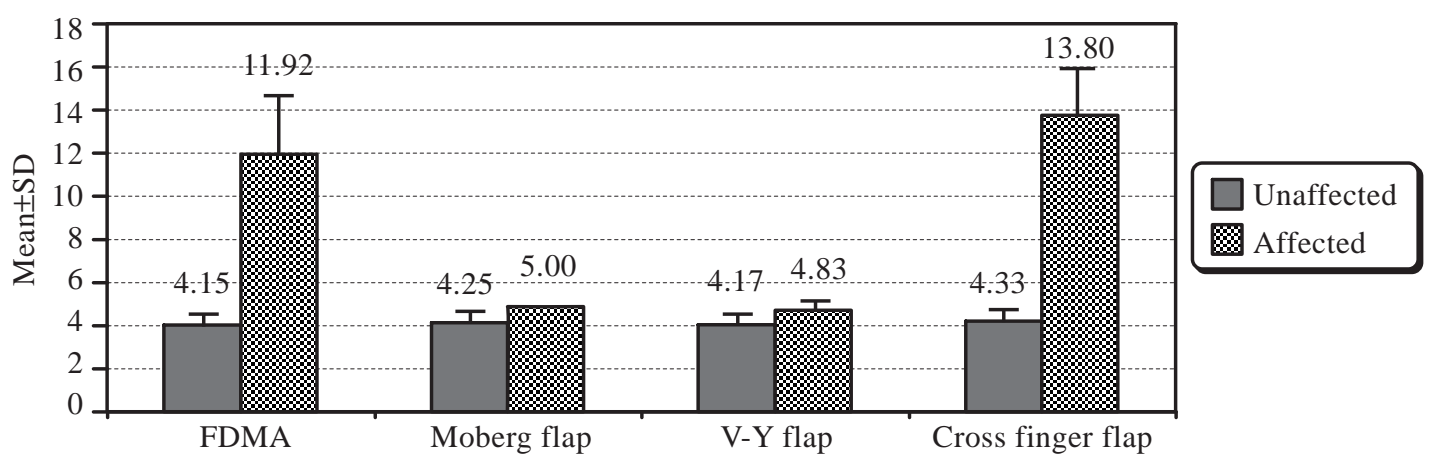

Table (3): Represents moving. PD in 4 groups from this table it was found that there were statistical significant differences between affected and unaffected groups in all domains. 
Table (4): Mono-filament test

\begin{tabular}{|c|c|c|c|c|c|c|c|c|}
\hline \multirow{2}{*}{ Affected } & \multicolumn{2}{|c|}{ FDMA } & \multicolumn{2}{|c|}{ Moberg flap } & \multicolumn{2}{|c|}{ V-Y flap } & \multicolumn{2}{|c|}{ Cross finger flap } \\
\hline & No. & $\%$ & No. & $\%$ & No. & $\%$ & No. & $\%$ \\
\hline Normal & 0 & 0.0 & 4 & 100.0 & 6 & 100.0 & 0 & 0.0 \\
\hline Diminished light touch & 11 & 84.6 & 0 & 0.0 & 0 & 0.0 & 15 & 100.0 \\
\hline Diminished protective sensation & 1 & 7.7 & 0 & 0.0 & 0 & 0.0 & 0 & 0.0 \\
\hline Loss of protective sensation & 0 & 0.0 & 0 & 0.0 & 0 & 0.0 & 0 & 0.0 \\
\hline Anesthetic & 1 & 7.7 & 0 & 0.0 & 0 & 0.0 & 0 & 0.0 \\
\hline
\end{tabular}

Table (4): Represents Mono-filament test in 4 groups, from this table it was found that $9 \%$ of patients who underwent FDMA flap regain normal sensation as regard to monofilament test, $84.6 \%$ developed diminished light touch, 7.7\% diminished protective sensation and $7.7 \%$ were anesthetic, on the other hand $199 \%$ patients who underwent Moberg flap and V-Y flap regain normal mono-filament test, regarding to cross finger flap, $199 \%$ of patients developed diminished light touch. There were statistical significant differences between FDMA in comparison with Moberg flap and V-Y flap. Also, there were statistical significant differences between Cross finger flap in comparison with Moberg flap and V-Y flap.

Table (5): Grip strength assessment.

\begin{tabular}{|c|c|c|c|c|}
\hline \multirow{2}{*}{ Grip } & FDMA & Moberg flap & V-Y flap & Cross finger flap \\
\hline & Mean \pm SD & Mean \pm SD & Mean \pm SD & Mean \pm SD \\
\hline Unaffected & $21.44 \pm 5.73$ & $33.00 \pm 2.58$ & $29.17 \pm 4.02$ & $28.40 \pm 5.87$ \\
\hline Affected & $11.26 \pm 3.07$ & $28.00 \pm 1.63$ & $25.56 \pm 4.01$ & $21.80 \pm 6.12$ \\
\hline$p$-value & 0.000 & 0.028 & 0.147 & 0.001 \\
\hline
\end{tabular}

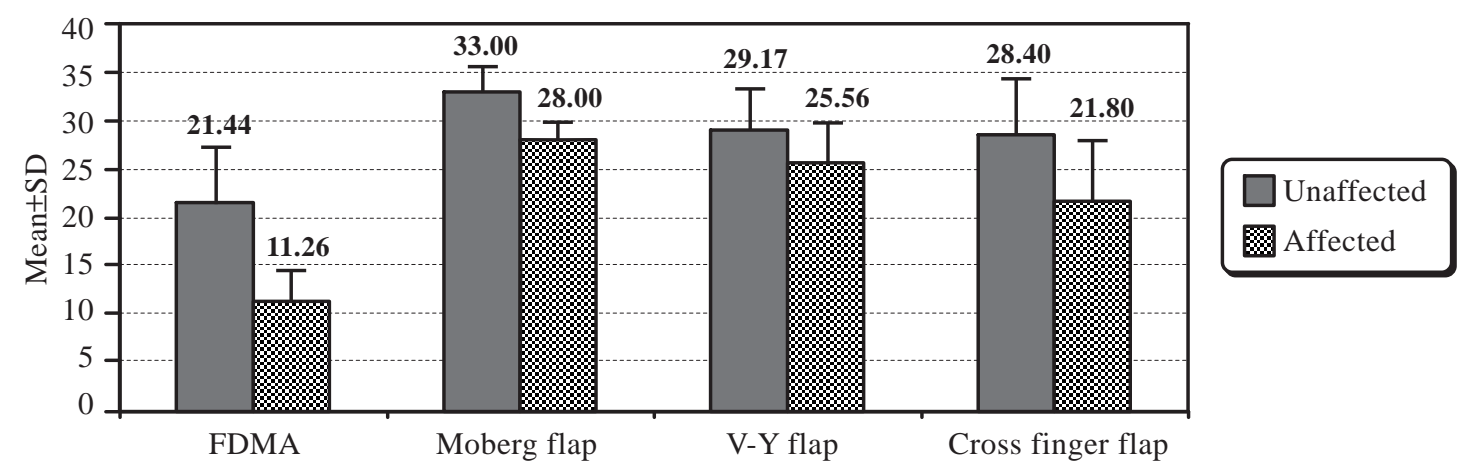

Table (5): Represents grip strength assessment in 4 groups, from this table it was found that there were statistical significant differences between affected and unaffected groups in all domains except V-Y flap group $p=(0.147)$.

Table (6): Pinch strength assessment.

\begin{tabular}{|c|c|c|c|c|}
\hline & FDMA & Moberg flap & V-Y flap & Cross finger flap \\
\hline & Mean \pm SD & Mean $\pm \mathrm{SD}$ & Mean \pm SD & Mean \pm SD \\
\hline \multicolumn{5}{|l|}{ Pulp to pulp: } \\
\hline Unaffected & $3.27 \pm 0.55$ & $4.88 \pm 0.25$ & $4.08 \pm 0.38$ & $4.18 \pm 0.78$ \\
\hline Affected & $1.59 \pm 0.77$ & $3.88 \pm 0.63$ & $3.08 \pm 0.49$ & $2.93 \pm 0.98$ \\
\hline$p$-value & 0.000 & 0.025 & 0.010 & 0.001 \\
\hline \multicolumn{5}{|l|}{ Pulp to lateral: } \\
\hline Unaffected & $3.45 \pm 1.58$ & $5.00 \pm 0.71$ & $4.08 \pm 0.80$ & $4.73 \pm 1.31$ \\
\hline Affected & $1.49 \pm 0.47$ & $3.00 \pm 0.41$ & $3.00 \pm 1.14$ & $3.27 \pm 1.57$ \\
\hline$p$-value & 0.000 & 0.019 & 0.121 & 0.018 \\
\hline \multicolumn{5}{|l|}{ Tripod: } \\
\hline Unaffected & $3.50 \pm 0.87$ & $6.00 \pm 0.00$ & $5.25 \pm 0.61$ & $5.53 \pm 1.34$ \\
\hline Affected & $1.74 \pm 0.67$ & $4.46 \pm 0.53$ & $3.92 \pm 0.92$ & $3.83 \pm 1.51$ \\
\hline$p$-value & 0.000 & 0.013 & 0.030 & 0.003 \\
\hline
\end{tabular}




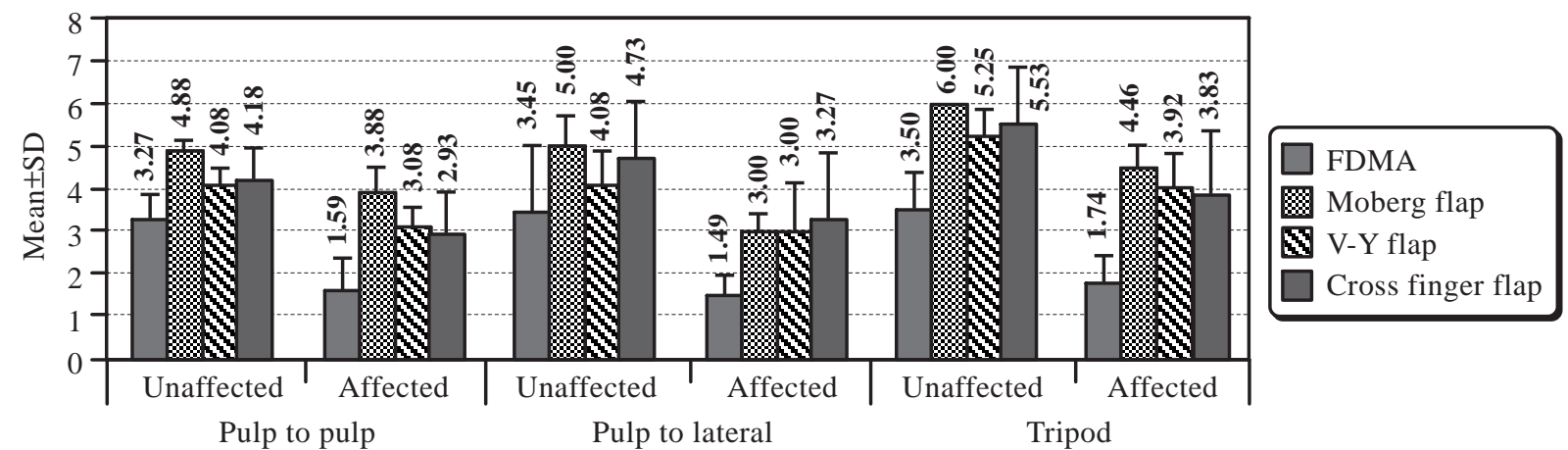

Table (6): Represents pinch strength assessment in 4 groups, from this table it was found that there were statistical significant differences between affected and unaffected groups in all domains as regard to pulp to pulp, pulp to lateral and tripod except for pulp to lateral in patients underwent V-Y flap $p=(0.121)$.

Table (7): Stereognosis score.

\begin{tabular}{|c|c|c|c|c|}
\hline \multirow{2}{*}{ Stereognosis } & FDMA & Moberg flap & V-Y flap & Cross finger flap \\
\hline & Mean \pm SD & Mean \pm SD & Mean \pm SD & Mean \pm SD \\
\hline Injured & $10.20 \pm 2.95$ & $11.78 \pm 0.67$ & $12.00 \pm 0.00$ & $11.33 \pm 1.18$ \\
\hline Contra & $11.02 \pm 3.32$ & $12.00 \pm 0.00$ & $12.00 \pm 0.00$ & $12.00 \pm 0.00$ \\
\hline$p$-value & 0.317 & 1.000 & 1.000 & 0.035 \\
\hline
\end{tabular}

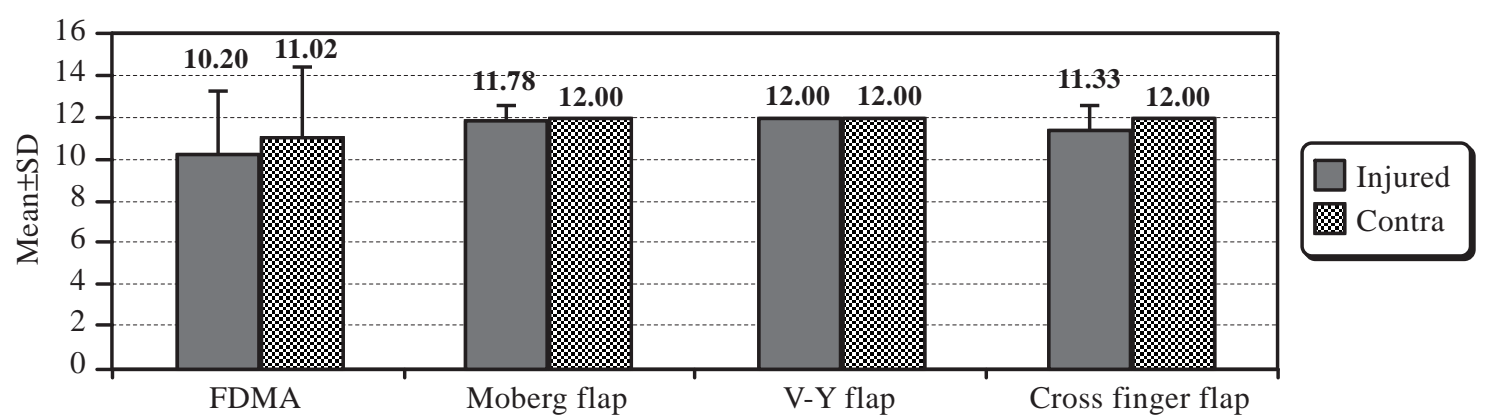

Table (7): Represents stereognosis score in 4 groups, from this table it was found that, there were no statistical significant differences between injured and contralateral sides in all groups except cross finger flap group $(p=0.035)$.

Table (8): Kapandji score.

\begin{tabular}{|c|c|c|c|c|}
\hline \multirow{2}{*}{ Kapandji score } & FDMA & Moberg flap & V-Y flap & Cross finger flap \\
\hline & Mean \pm SD & Mean \pm SD & Mean \pm SD & Mean \pm SD \\
\hline Injured & $9.38 \pm 1.45$ & $6.75 \pm 0.50$ & $7.17 \pm 0.41$ & $6.27 \pm 0.96$ \\
\hline Contra & $9.00 \pm 0.00$ & $9.00 \pm 0.00$ & $9.00 \pm 0.00$ & $9.00 \pm 0.00$ \\
\hline$p$-value & 0.000 & 1.011 & 0.001 & 0.000 \\
\hline
\end{tabular}

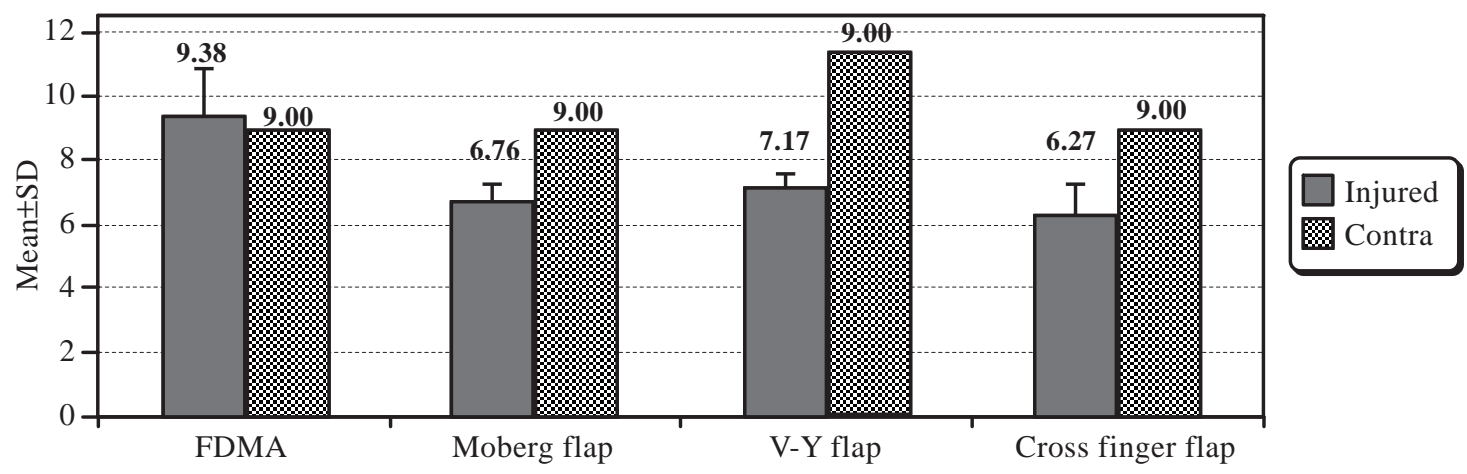

Table (8): Represents Kapandji score in 4 groups, from this table it was found that there were statistical significant differences between injured and contralateral sides in all groups. 
Fig. (3): Cross finger flap.

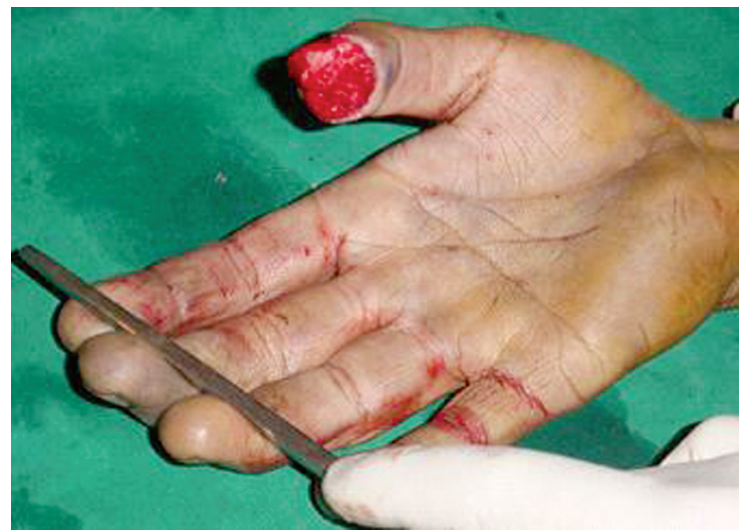

(A): Initial presentation: Distal thumb amputation.

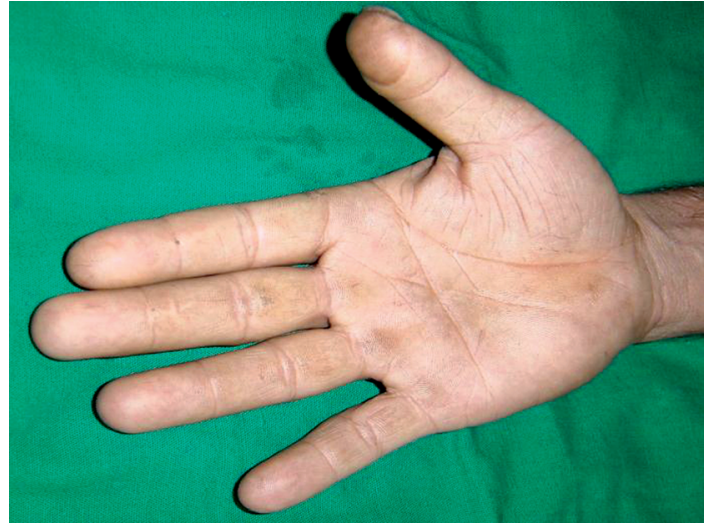

(C): The result at 3 months postoperative.

Fig. (4): First dorsal metacarpal artery flap.

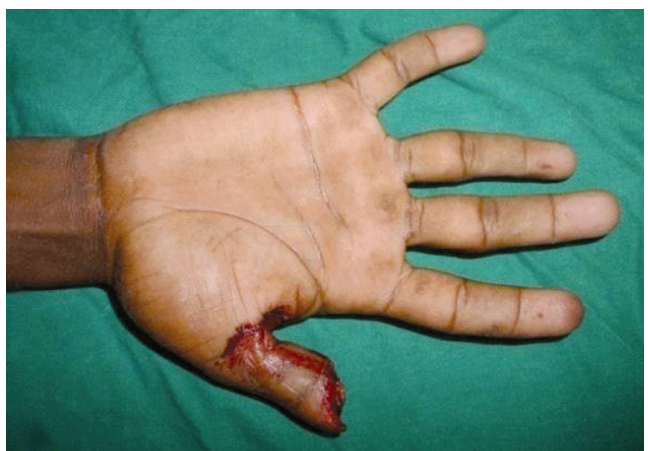

(A): Initial presentation: Thumb demonstrating tip amputation.

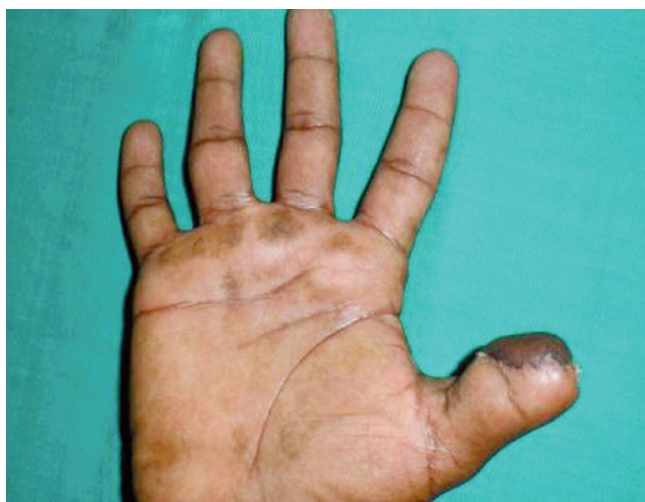

(C): The result at 3 months postoperative.

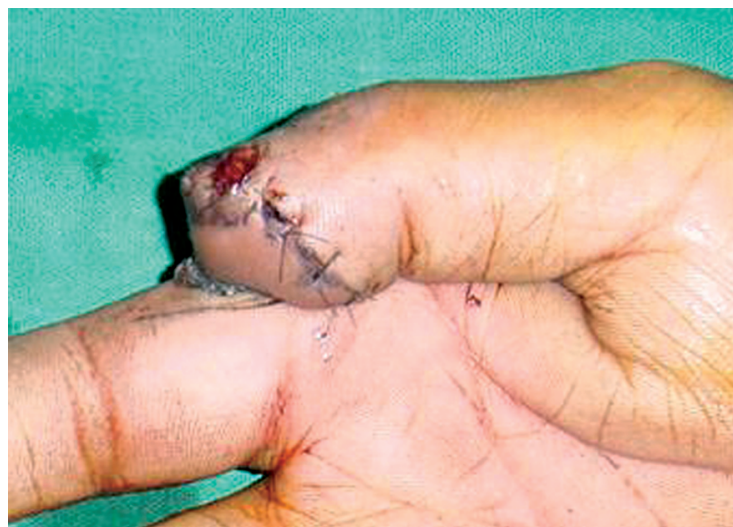

(B): Cross-finger flap from the index finger.

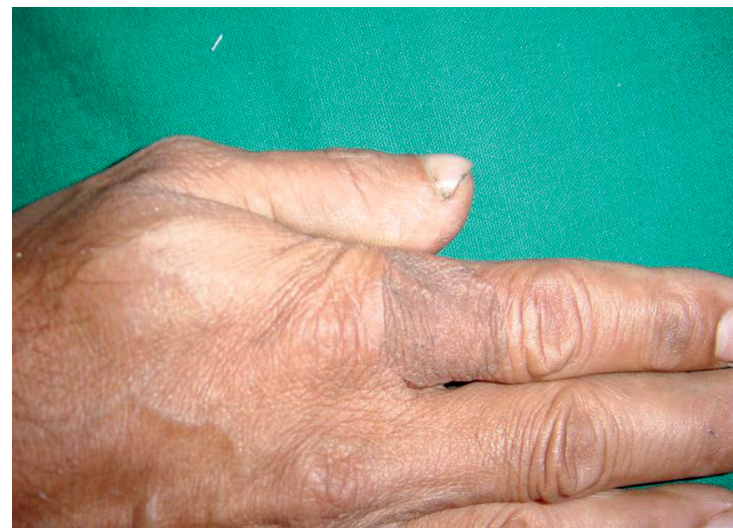

(D): The grafted donor site.

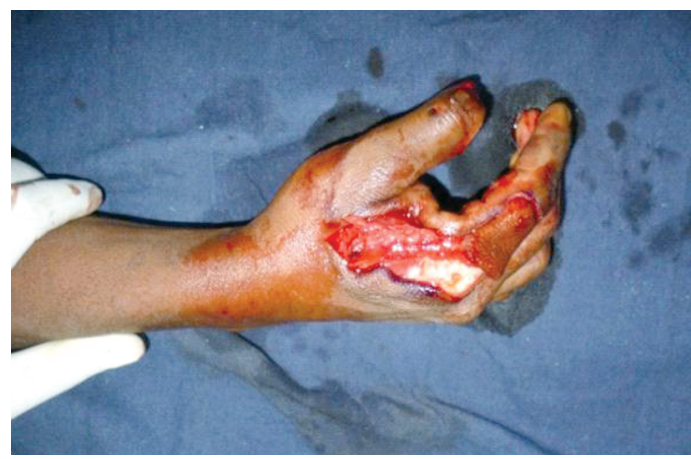

(B): Intraoperative photograph: Raising of the first dorsal metacarpal artery flap.

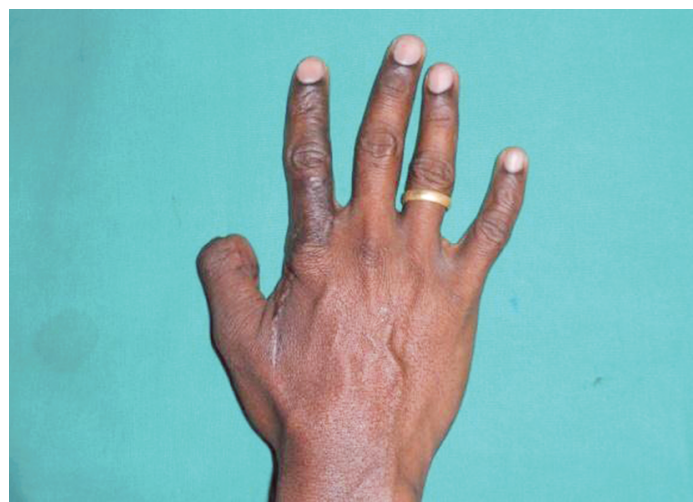

(D): The donor site grafted and healed well. 
Fig. (5): Moberg flap.

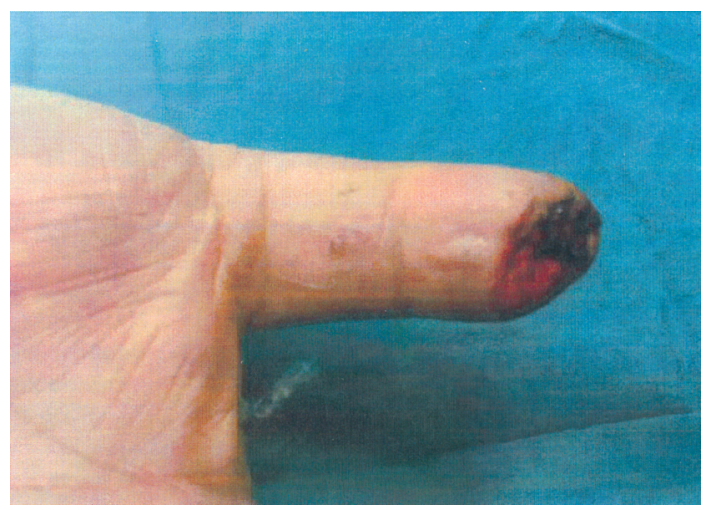

(A): Initial presentation: Thumb demonstrating tip amputation.

Fig. (6): V-Y Flap.

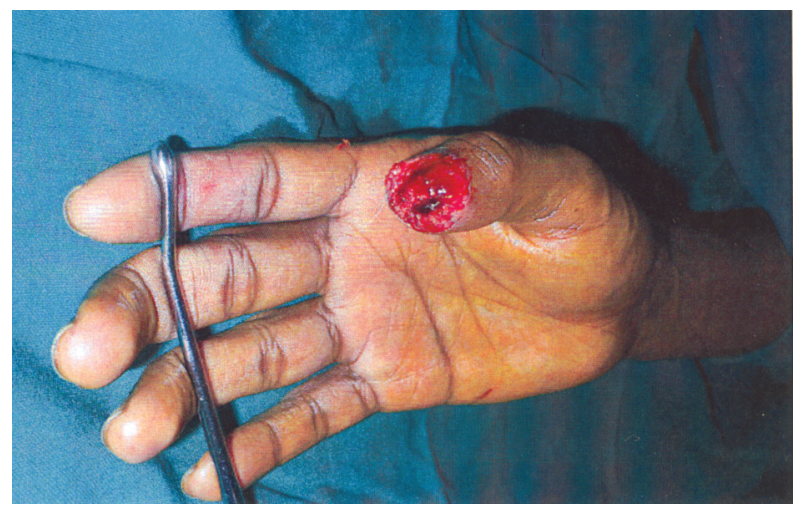

(A): Initial presentation: Thumb demonstrating tip amputation.

\section{DISCUSSION}

Thumb is critical for hand function and it is reflected by many papers on its different modalities of reconstruction after traumatic loss. The determinants for good practical result are the right position of the thumb opposable to the current fingers, a movable CMC joint, sensate and nontender tip, security of the interphalangeal and metacarpophalangeal joint and strength satisfactory to oppose the force of the fingers [7].

In this study there were thirty-eight patients of distal thumb amputation who were classified into four groups according to the method of reconstruction.

These 38 patients were studied with mean age 30 year old, 35 were males and 3 were females. Distal thumb amputations rarely result in a functional deficit and may be termed a "compensated amputation". These patients require a sensate and supple tip, which can be provided by glabrous and nonglabrous skin flaps. These include the homodigital flaps (Moberg, V-Y advancement) and the

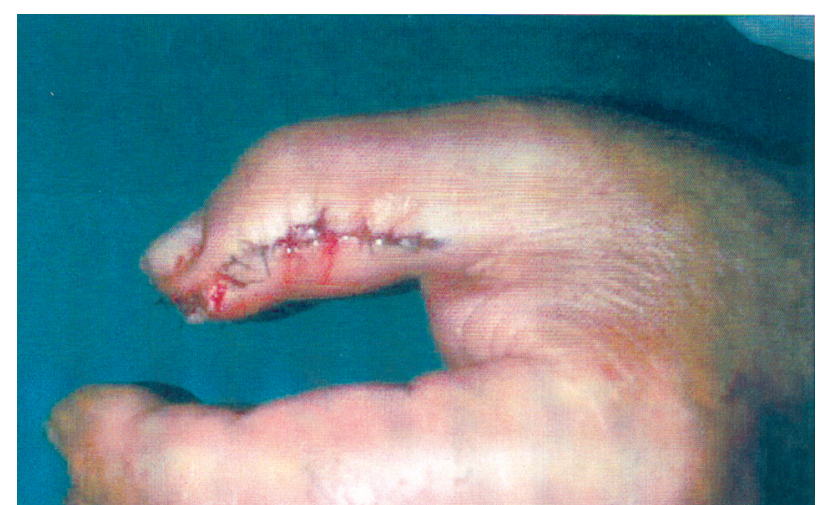

(B): Neurovascular advancement (Moberg) flap advanced to cover defect of tip.

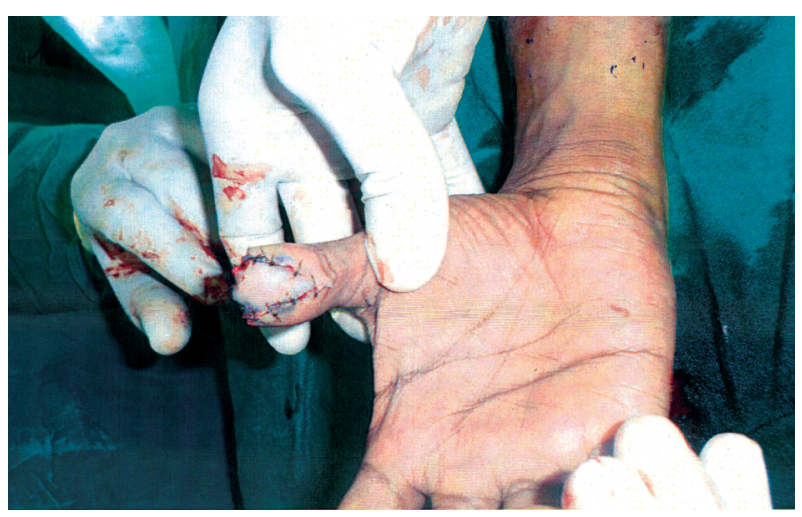

(B): V-Y Flap: Immediate post-operative.

heterodigital flaps (first dorsal metacarpal artery and cross finger flap).

Muyldermans and Hierner, [8] find an average 2PD of $10.57 \mathrm{~mm}$ after an FDMA flap for thumb reconstruction and Jung et al., [9] note that the average 2PD in Moberg flaps was $5.6 \mathrm{~mm}$.

At a minimum follow-up of static and moving 2PD one year post operative, we have found that the mean was significantly better in patients who underwent homodigital flaps (Moberg and V-Y advancement $)(5.00 \mathrm{~mm})$ and $(4.83 \mathrm{~mm})$ respectively, compared with that in patients underwent heterodigital flaps, FDMA and Cross finger (11.92) and (13.80) respectively.

Our results were consistent with the findings of Muyldermans and Hierner and Jung et al.

We have found that $199 \%$ of patients who underwent Moberg and V-Y advancement flaps regain normal sensation in monofilament test while $84.6 \%$ developed diminished light touch using FDMA flap cover compared with $199 \%$ of patients developed diminished light touch using cross finger flap cover. 
The mean grip and pinch strength were lower in affected hands compared with the contralateral sides in all groups and did not reach the values of the contralateral side at one year follow-up.

On the pickup test 11 out of 13 patients who underwent FDMA flap could pickup all 12 objects while the remaining two patients having difficulty in picking up small objects, all patients who underwent Moberg flap and V-Y flap could pickup all 12 objects. 14 out of 15 patients underwent Cross finger flap could also pickup all objects and the last patient could not pickup small objects. This could probably be attributed to the absence of the nail.

\section{Conclusion:}

The use of sensate homodigital flaps (Moberg and $\mathrm{V}-\mathrm{Y}$ advancement) gives better results than heterodigital flaps (FDMA and Cross finger).

The mean grip and pinch strength were lower in affected hands compared with the contralateral sides in all groups and did not reach the values of the contralateral side at one year follow-up.

\section{REFERENCES}

1- Robert W. Beasley: Tendon transfer, thumb reconstruction \& sensory island flaps, Beasley's surgery of the hand, $(19,20)$ 319: 369, 2003.
2- Lemon R.N.: Neuralcontrolof dexterity: What has been achieved? Experimental Brain Research, 128: 6-12, 1999.

3- Voiget C.: Tendon injuries of the hand. Chirurg, 73: 74464, 2002.

4- Parvizi D., Koch H. and Friedl H.: Analysis of functional outcome after posttraumatic thumb reconstruction in comparison to non reconstructed amputated thumbs at the proximal phalanx of the thumb ray: A mid-term followup with special attention to the Manchester-modified M2 DASH questionnaire and effect size of Cohen's d. J. Trauma, 72 (2): 33-40, 2012.

5- Graham D.J., H. Venkatramani and S.R. Sabapathy: Current Reconstruction Options for Traumatic Thumb Loss. J. Hand Surg. Am., 41 (12): 1159-1169, 2016.

6- Sabapathy S.R., Venkatramani H. and Bharathi R.R.: Functional evaluation of a great toe transfer and the osteoplastic technique for thumb reconstruction in the same individual. J. Hand Surg. Br., 28 (5): 405-408, 2003.

7- Sabapathy S.R., Venkatramani H. and Bhardwaj P.: Reconstruction of the thumb amputation at the carpometacarpal joint level by groin flap and second toe transfer. Injury, 44: 370-5, 2013.

8- Muyldermans T. and Hierner R.: First dorsal metacarpal artery flap for thumb reconstruction: A retrospective clinical study. Strategies Trauma Limb Reconstr., 4: 27 33, 2009.

9- Jung G.J., Kim J.S., Lee D.C., Roh S.Y. and Yang J.W.: Comparison between Moberg flap and second toe pulp free flap for coverage of tip amputation of thumb. J. Korean Soc. Plast. Recontr. Surg., 35 (5): 527-532, 2008. 